\title{
LiftOff to Best Practices in K-12 Engineering Curriculum Design
}

\section{Ms. Margaret Baguio, University of Texas at Austin}

Margaret Baguio is the Sr. Education and Outreach Coordinator for NASA's Texas Space Grant Consortium in Austin, Texas. She has worked for over thirty years in youth development and education. During that time, Margaret has worked in public schools, for the Texas Cooperative Extension Service 4-H \& Youth Development Program, managed a USDA Science and Literacy project for at-risk youth, and promoted space education to students, teachers and the general public through the Texas Space Grant Consortium.

Margaret received her Bachelor of Science degree and Secondary Teacher Certification from Texas State University and Masters in Education from University of Houston. In addition, she has completed postgraduate studies at Texas A \& M University.

\section{Dr. Wallace T. Fowler P.E., University of Texas, Austin}

Wallace Fowler holds the Paul D. and Betty Robertson Meek Centennial Professorship in the Department of Aerospace Engineering and Engineering Mechanics at the University of Texas at Austin, where he has been on the faculty since 1965. His areas of teaching and research are dynamics, orbital mechanics, spacecraft and space mission design, and aircraft flight testing. He is the recipient of several teaching awards, including the AIAA / ASEE John Leland Atwood Award and the ASEE Fred Merryfield Design Award. He is a member of the University of Texas at Austin Academy of Distinguished Teachers. He is a fellow of both the ASEE and the AIAA. He served as President of ASEE in 2000-2001.

\section{Mrs. Susana Ramirez, PSJA ISD}

Susana Ramirez currently serves as Elementary Science Coordinator for the Pharr-San Juan-Alamo School District in the Rio Grande Valley of Texas. She is currently in her 13th year with the district. She has taught second grade and has taught science in fifth, seventh, and eighth grade. She served as a professor at the University of Texas Pan American (UTPA) in fall 2006. She was a member of the UTPA Regional Collaborative for Science 2002-07, a member of the Texas Regional Collaborative for Science 2007 -12, and a member of Texas Earth and Space Science Revolutions 2007-12. She was selected as a 2010 NASA Heliophysics Ambassador and received the 2009 Texas Medical Association Ernest and Sarah Butler Award for Excellence in Science Teaching. She was selected as the 2008 Toyota Science Teacher of the Year for Texas and Texas Science Mentor Teacher of the Year 2005. She is Grant Coordinator and Past President of the Rio Grande Valley Science Association, current Treasurer for the Texas Education Leadership Association, current President for the Texas Council of Elementary Science and and is currently working with the NASA's Texas Space Consortium, UT of Austin, and UTPA on a grant awarded from NASA in the amount of $\$ 750,000.00$. She served as the Program Coordinator of the National Science Teachers Association in San Antonio, Texas 2013 .Susana has been selected four times to participate in the LiftOff Summer Institute at NASA JSC 2009, 2011, 2012, and 2013. She currently serves as Curriculum Development Committee Chair for the LiftOff Summer Institute. 


\section{LiftOff to Best Practices in K-12 Engineering Curriculum Design}

The NASA Education Program ${ }^{1}$ has 52 Space Grant Consortia ${ }^{2,3}$ spread across the United States. A primary focus of the consortia is the improvement of science, technology, engineering, and mathematics (STEM) education at all levels to enhance our nation's high technology workforce.

One of the 52 Space Grant Consortia has offered a four-to-five day summer program for K-12 educators at NASA Johnson Space Center (JSC) every year since 1990. Space Grant's primary focus and highest leverage in pre-college education is the professional development of K-12 educators. The objective of the LiftOff Summer Institute ${ }^{4}$ is to provide the attendees with materials that can be used both to excite their students about STEM learning across disciplines and to meet state, national and common core standards. The consortium has established the following goals for its K-12 educator development.

- Inspire and motivate students at all levels to pursue careers in science, technology, engineering and mathematics (STEM).

- Enhance K-12 educator knowledge in STEM cross-curricular space related fields.

- Increase K-12 student knowledge in STEM education through age-appropriate space related activities.

- Increase underrepresented and underserved participation.

- Enhance career exploration by including space science professionals, NASA employees, and NASA-sponsored scientists, technical and engineering experts as role and career models.

In 1990, the consortium imported a workshop from NASA Ames ${ }^{5}$ as the first offering of a program that became the "LiftOff" program, a nationally competitive week-long in-service professional development training for middle and high school teachers. A collaborative effort of consortium affiliates, NASA, and industry, the workshops are organized around an aerospace or space science theme drawn from NASA's diverse engineering and scientific research programs. The program combines the strengths of the collaborators to enrich teaching and learning of STEM topics. During a recent evaluation, $95 \%$ of those responding rated the LiftOff Summer Institute as "extremely effective." A comprehensive evaluation of the annual programs and follow-up with participants allows us to document program successes, how materials are being used, and numbers reached through this train-the trainer workshop. In the past five years, 250 teachers have attended LiftOff. On an average, these 250 teachers have utilized the materials and training with 25,000 students, and trained an additional 12,000 teachers. In the words of one participant, "LiftOff Summer Institute was an everlasting experience. I can't wait until school starts! I am so excited about sharing everything that I experienced, not only with my students, but with fellow teachers and colleagues."

The paper will present the history of the LiftOff program, an analysis of how it has changed over the past 25 years, a listing of program topics, a typical program agenda, program goals and outcomes, metrics, participant feedback, program evaluation results, anecdotal data, and best practices for replicating this program. 


\section{History of the Program}

In 1990, the Texas Space Grant Consortium created the "LiftOff" program, a week-long professional development training for middle and high school teachers. A collaborative effort of Texas Space Grant Consortium members and affiliates, NASA, and industry, the workshops are organized around an aerospace or space science theme drawn from NASA's diverse engineering and scientific research programs. The program is designed to combine the strengths of the collaborators to enrich teaching and learning of science, mathematics, technology and engineering.

Themes for the LiftOff Summer Institute change each year based upon NASA missions, current topics, and needs of professional educators. Past program topics include:

\section{LIFTOFF WORKSHOPS 1990 - Present}

\begin{tabular}{|l|l|}
\hline \multicolumn{1}{|c|}{ Year } & \multicolumn{1}{|c|}{ Title of LiftOff Workshop } \\
\hline 1990 & CRAF Cassini Workshop \\
\hline 1991 & Lunar Base Design \\
\hline 1992 & Biomedical Aspects of Space Operations \\
\hline 1993 & Off-Planet Exploration \\
\hline 1994 & Roving the Red Planet \\
\hline 1995 & ISS \\
\hline 1996 & Closing the Loop \\
\hline 1997 & Remote Sensing \\
\hline 1998 & On the Edge \\
\hline 1999 & Catch a Falling Star, Comets, Asteroids, Meteorites \\
\hline 2000 & Return to the Red Planet \\
\hline 2001 & 2001: An Edu-Space Odyssey \\
\hline 2002 & Have Spacesuit Will Travel \\
\hline 2003 & Exploring the Unknown \\
\hline 2004 & Mars: Journey to the Red Planet \\
\hline 2005 & Spinoffs: Bringing Space Down to Earth \\
\hline 2006 & Return to the Moon \\
\hline 2007 & Robotics and Space Exploration \\
\hline 2008 & Space Travel: It's Out of This World! \\
\hline 2009 & Celestial Travelers \\
\hline 2010 & Design a Mission to the Moon \\
\hline 2011 & Earth's Reflections: A View from Above \\
\hline 2012 & Space Innovations and Exploration \\
\hline 2013 & Rockets to Robots \\
\hline
\end{tabular}

The first three years of the program teamed groups of high school students with their classroom teacher for the week in Houston. Teachers quickly shared their need to have professional development without having to monitor students and the program became a teachers-only 
program. Hands-on activities, lectures, and field trips are now combined with daily sharing of space science activities and materials that were developed by or been successful to participants.

The workshop features presentations by NASA scientists and engineers, astronauts, and university and industry partners such as the Lunar and Planetary Institute ${ }^{6}$, the University of Texas at Austin ${ }^{7}$, and the United Space Alliance ${ }^{8}$ for the most recent discoveries in space science, while incorporating hands-on activities from NASA curriculum. Visits to the Houston Museum of Natural Science ${ }^{9}$, Galveston Moody Gardens ${ }^{10}$, George Observatory ${ }^{11}$, and missions in the Challenger Center ${ }^{12}$ provide quality educational materials for incorporation into lessons and activities.

In 2013, NASA Johnson Space Center's Education Department merged their Middle School Aerospace Scholars ${ }^{13}$ program with the LiftOff Summer Institute, thereby funding ten additional teachers annually. LiftOff is designed to include material relevant to teachers in many fields (such as biology, physics, chemistry, earth science, environmental science, math, and technology). We utilize a train-the-trainer model, where we train the teacher during LiftOff and then they return to their school district and train other teachers. The train-the-trainer concept works well as the participants selected to attend annually average training over 1,000 additional educators in their respective districts and work with approximately 7,000 students upon their return. Due to the popularity and noteworthy educational content of this workshop, other states now send representatives to the LiftOff Summer Institute. Inquiry based strategies ${ }^{14}$ and experiential learning ${ }^{15}$ allows these educators to incorporate techniques into their teaching to actively engage student learning in math, science, and technology.

The LiftOff workshops have shown that the excitement that teachers and students feel about space science and exploration can be tapped to enrich math, science, and technology classes. The workshops also provide teachers the rare - for some, unique - opportunity to spend a week working with professional scientists and engineers.

How the program has changed over the years

Initially, LiftOff was for Texas teachers only. When Space Grant Consortia in other states heard about the program and wanted to participate, we opened the selection process nationwide. Any teacher accepted from out of the state of Texas must solicit their own funding for all workshops costs and transportation. When a Texas teacher is selected, the Texas Space Grant Consortium (TSGC) pays all their expenses.

In 1991, the program was coordinated by the second author, then the Associate Director of TSGC. In the next year, 1992, the program was coordinated by Dr. Bill Alter, then the research coordinator for The University of Texas at San Antonio. After that, because TSGC did not have a full-time Education and Outreach member on its staff, the program was coordinated by a parttime TSGC planner along with a sub-contract with the Universities Space Research Association's Lunar and Planetary Institute (LPI). LPI is located in Houston and had strong contacts at NASA Johnson Space Center. The TSGC planner for 1993-1999 was Calina Seybold, a PhD candidate at the University of Texas at Austin. After earning her PhD in 2000, Dr. Seybold took a position with Cal Tech / NASA Jet Propulsion Laboratory (JPL) in 
California. During the period from 1993 to 1999, TSGC handled the agenda, application process and logistics while LPI handled the production of learning materials, speakers, and tours. When a full-time Education and Outreach Coordinator (the first author) was hired at TSGC, a LiftOff planning committee was formed and the program became much more tightly structured.

Members of the committee include NASA engineers, NASA education staff, former participants, space industry staff, and TSGC staff.

Initially, our focus was on providing teachers with a professional development opportunity that supports a space science theme. We would select a theme around a NASA mission or topic that we knew teachers would find interesting.

As our knowledge about the importance of STEM education increased, so did our basis for program selection, topics, and themes. The primary guiding principle for LiftOff can be summed up in a quote from former Astronaut, Dr. Mae C. Jemison, President of BioSentient Corporation, "In order for all students - regardless of age, gender, cultural or ethnic background, disability, aspiration, inspiration or motivation - to achieve in science, they must have access of highlyskilled professional teachers, adequate classroom time dedicated to science learning and quality science learning materials."

Teachers shared in evaluation reports that they did not feel skilled to teach many science concepts or topics. For example, many elementary and middle school teachers reported they may have had one general science course and maybe no astronomy courses to graduate from college, yet they must teach students about the formation of the solar system, characteristics of the planets, phases of the moon, etc. They needed to understand the concepts themselves before teaching to their students.

Our goal became: to provide professional development of the highest quality, find topics that gave teachers skills and background knowledge needed to teach concepts, and provide opportunities for teachers to share ideas and concepts on successful STEM engagement in the classroom. Given that, we selected the following criteria based on guidelines provided by Building Engineering and Science Talent (BEST) Commission, National Science Education Standards and National Science Resources Center: ${ }^{16}$

1. Challenging Content/Curriculum

2. An Inquiry Learning Environment

3. Defined Outcomes/Assessment

4. Sustained Commitment/Support

LiftOff allows TSGC to continue to build upon its partnership with the NASA JSC. For participants, visiting a NASA Center, interacting with scientists and engineers, and gaining expertise in areas where they previously were not comfortable teaching, are all highlights.. LiftOff also enhances our partnership with Space Grant Consortia in those other states that choose to send an educator to participate in this week-long event.

Reaching underrepresented groups is an important focus of our activities. To provide support to educators from NASA Explorer Schools ${ }^{17}$ and Summer of Innovation ${ }^{18}$ we now provide priority 
space for educators from programs reaching underserved students in underrepresented areas of the state. This is a means for providing curriculum-rich resources to educators in under-utilized areas of the state and allows us to provide resources for those serving under-represented audiences.

Knowing that teachers gain valuable information from each other, a "Teacher Feature" activity was added to the agenda. Teacher Feature invites participants selected for the program to submit a classroom activity that they have found beneficial to their students. Teachers receive a flash drive with all teacher features, speaker power point presentations, and resources. Each teacher is given 5-10 minutes during the weeklong workshop to describe their activity, show examples of student work, videos, or power point presentations. This has become one of the most popular additions to the week.

\section{$\underline{\text { Program Goals and Outcomes }}$}

Although our goals have changed on specifics each year, the overall goals remain the same.

- Enhance K-12 educator knowledge in space related fields.

- Increase K-12 student knowledge in STEM education through age-appropriate space related activities.

- Inspire and motivate students at all levels to pursue careers in science, technology, engineering and mathematics (STEM) by providing curriculum-rich training to classroom teachers.

- Increase underrepresented and underserved participation.

- Enhance career exploration by including space science professionals, NASA employees, and NASA-sponsored scientists, technical and engineering experts as role and career model.

- Assist K-12 teachers in exciting their students to learn math and science through space based activities.

- Direct programs to areas of the state that have few space related resources.

\section{Program Planning and Implementation}

Planning for the LiftOff Summer Institute begins at least nine months prior to the Institute. Recommended themes are collected from teacher evaluations, program partners, and current NASA missions and activities. Final themes are then submitted to the planning committee for suggested speakers, activities, and value to teachers. The location for the conference is booked and hotel rooms reserved. The final topic is selected by the end of October and announced at the Texas State Science Teacher Association conference which is attended by over 6,000 science teachers annually in November. TSGC sponsors an exhibit at the conference and former LiftOff attendees volunteer to work at the booth, conducting hands-on activities, distributing bookmarks with LiftOff information, and sharing their experiences at LiftOff.

The website announcing the LiftOff Summer Institute is ready by November, along with the online application. An announcement goes out to all Space Grant Consortia in the nation and to all STEM teachers and coordinators in the State of Texas to publicize the LiftOff Summer Institute and encourage teachers to apply. 
In February, a committee meeting is held during the Space Exploration Educator Conference ${ }^{19}$ in Houston, Texas. Committee members identify speakers, visit NASA facilities for possible tour sites, and review curriculum for inclusion in the institute, visit restaurants for meetings and dinners, and coordinate activities with the NASA Johnson Space Center Education staff.

As speakers are contacted, we ask for their availability throughout the week. It may be necessary to move individual presentations due to NASA work and scheduling. The final agenda is usually not finalized until the week prior to the event due to NASA projects and schedules.

Astronauts and Teachers: The inspirational value of having astronauts sharing their experiences with teachers is immense. Astronauts have been featured speakers at most of the LiftOff programs. An example of the teacher enthusiasm generated by astronauts follows. Astronaut Story Musgrave ${ }^{20}$ gave an after-dinner talk to LiftOff participants in the summer of 1992. His talk consisted of showing photos that he had taken while on orbit in the Space Shuttle. His first slide was a photograph of the crew of the shuttle on the mid-deck of the shuttle eating. It looked a lot like you might imagine - everyone (except Story) eating "space food" (food in pouches squeezing food into their mouths), drinking from pouches of liquid, etc. Story's comment was that they were doing it wrong. Everyone had their heads facing "up" the same direction - like they were in a room on Earth. He then showed the next slide - he had rearranged the other astronauts. They were "sitting" on the walls, the floor, and the ceiling - their heads facing "up" in different directions. Story's point was that if you got a chance to go to orbit, take advantage of the new environment and do things in a way that you can't do them on Earth. Story continued with his slides, showing storms from orbit, beautiful colors in particular parts of the ocean, rivers, etc. On one slide, showing the area around Cairo, Egypt, he pointed out an area of lighter colored sand. The lighter colored sand was the sand around the pyramids where all of the tourists had walked, turning the weathered side of the sand particles under and exposing their lighter unweathered sides. It was a full-Earth geography lesson in about 100 slides. He continued for over an hour, and it was getting late. Near the end of the talk, he mentioned that he had taken more than 2000 photos from orbit. When he ended his talk, the prevailing sentiment among the teachers was that they would have stayed all night if he would have gone and gotten the rest of his photos.

The prevailing sentiment from participants about astronaut presentations is, "Wow! Amazing! I feel valued as a teacher hearing these amazing individuals tell me how important I am."

Teachers enjoy having the astronaut presentations to share with their students. Another teacher shared, "Having an astronaut share with us the numerous times they applied to be an astronaut before being selected is such a valuable lesson. I tell my students each failure is a piece of experience that becomes steps to success, if they persevere."

Susana Ramirez, a Liftoff Alumni teacher stated "The LiftOff Summer Institute is one of the best professional development programs I have ever attended. The content provided fits directly into the topics that I am required to teach but gives me hands-on, inquiry lessons that students find engaging while also increasing my STEM background knowledge. I teach 100 Hispanic students and they are all on free or reduced lunch. Because of the knowledge I have gained from Liftoff, my school district asks me to conduct professional development training for other teachers. This 
allows materials from LiftOff to be used by even more students. By having women and minorities that are NASA engineers and astronauts as speakers, I have been able to share motivational and inspiring stories in which my students can relate. This inspired me to want to get more girls involved. I now reach out to elementary age girls for week-long summer STEM camps and after school clubs to instill in them a love for science. "'

Engineers: Interacting with engineers and learning first-hand about their daily work is interesting and inspiring. We have had teachers invite speakers from LiftOff to their classrooms to speak directly with their students. NASA engineer, Jerry Woodfill, gave a motivational presentation at LiftOff about "Failure is NOT an option: Steps leading to success." One teacher shared, "Many of our students have made mistakes and they all need to be motivated and overcome their 'fear, frustration, and failure'. I am so excited that he has agreed to speak to my students. It will definitely make a difference in their lives." Heather Paul, NASA JSC spacesuit engineer, conducts distance learning events with LiftOff teacher classrooms. This experience motivates students and provides a first-hand experience in spacesuit design.

Tours and Field Experience: One example of a tour and field experience is a visit to the Houston Museum of Natural Science. We provide LiftOff participants with the opportunity to conduct a Challenger Mission. A Challenger Learning Center mission is more than a field trip or a computer game. The mission simulations are learning environments embedded with activities and lessons aligned with national Next Generation Science Standards (NGSS) ${ }^{21}$ and Common Core State Standards (CCSS) ${ }^{22}$. While teachers become astronauts and engineers at Challenger Learning Centers they are solving real-world problems as they share the thrill of discovery on missions through the Solar System. One teacher stated, "The Challenger mission was very stressful but extremely worthwhile. This helped me understand what some of my lower functioning students must go through when faced with the pressure of having to complete a difficult task in a short amount of time." After participating, LiftOff teachers learn how to apply for a grant from the Astronaut Alumni Association to bring their students to conduct a Challenger Mission. Many LiftOff participants have taken advantage of this opportunity.

Typical Program Agenda:

\begin{tabular}{|c|c|c|c|c|c|}
\hline $\begin{array}{l}\text { Sunday, } \\
\text { June } 23\end{array}$ & $\begin{array}{c}\text { Monday, } \\
\text { June } 24\end{array}$ & $\begin{array}{c}\text { Tuesday, } \\
\text { June } 25\end{array}$ & $\begin{array}{l}\text { Wednesday, } \\
\text { June } 26\end{array}$ & $\begin{array}{c}\text { Thursday, } \\
\text { June } 27\end{array}$ & $\begin{array}{c}\text { Friday, June } \\
28\end{array}$ \\
\hline $\begin{array}{l}\text { Airport } \\
\text { Pick Ups }\end{array}$ & $\begin{array}{c}\text { 7:45 am } \\
\text { Depart Hotel } \\
\text { for Gilruth } \\
\text { 8:30 am } \\
\text { NASA } \\
\text { Welcome } \\
\text { Susan White, }\end{array}$ & $\begin{array}{c}\text { 7:45 am } \\
\text { Depart Hotel } \\
\text { for Gilruth } \\
\text { 8:15 am } \\
\text { Teacher } \\
\text { Feature }\end{array}$ & $\begin{array}{c}\text { 7:45 am Depart } \\
\text { Hotel for } \\
\text { Gilruth } \\
\text { 8:15 am } \\
\text { Teacher } \\
\text { Feature }\end{array}$ & $\begin{array}{c}\text { 7:45 am } \\
\text { Depart Hotel } \\
\text { for } \\
\text { Gilruth } \\
\\
\text { Teacher } \\
\text { Feature }\end{array}$ & $\begin{array}{c}\text { Pack Cars } \\
\text { 8:00 am } \\
\text { Depart for } \\
\text { Space Center } \\
\text { Houston } \\
\text { 8:30 am }\end{array}$ \\
\hline
\end{tabular}




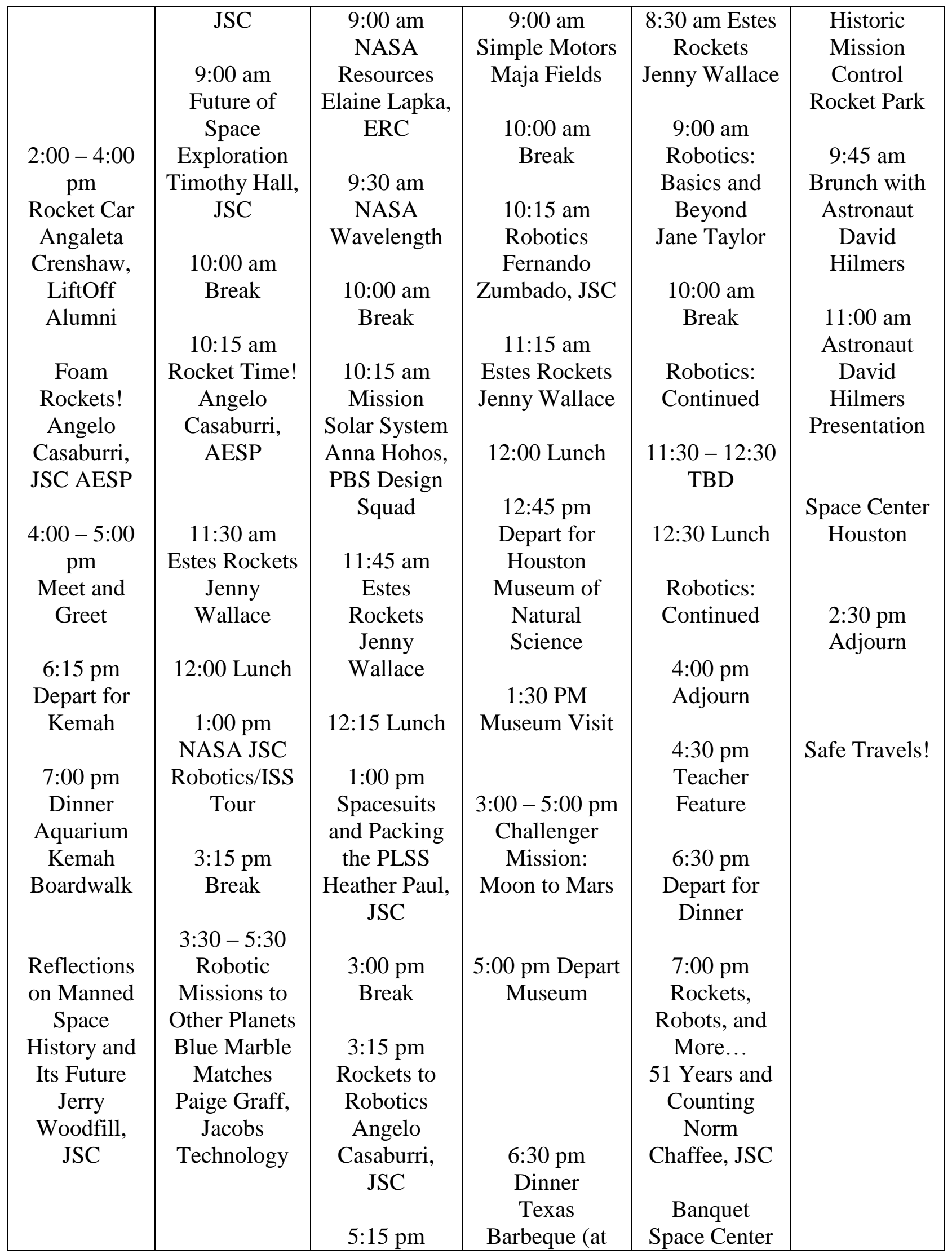




\begin{tabular}{|c|c|c|c|c|c|}
\hline & $6: 00 \mathrm{pm}$ & Return to & Hotel $)$ & Houston & \\
Dotel & & Destiny & \\
Theatre & & \\
& Dinner & & & Starship & \\
Fuddruckers & $6: 30 \mathrm{pm}$ & & Gallery & \\
& & Depart Hotel & & & \\
& & $6: 45 \mathrm{pm}$ & & & \\
& & Dinner & & & \\
& & & & \\
& & & & & \\
& & & & & \\
& & & & & \\
\end{tabular}

Curriculum and Activities: Curriculum topics and activities are selected based on the theme for LiftOff. For example, the theme for LiftOff 2013 was Rockets to Robots. During LiftOff teachers made Rocket Cars, Foam Rockets, Pop Rockets, Paper Rockets, Robotic Arm, Simple Motors, and learned how to build and program Lego Mindstorm Robots. Scientists and engineers at NASA JSC hosted the LiftOff participants in the Robotics Laboratory at JSC. Links below provide samples of the activities:

Robotic Arm: http://www-

tc.pbskids.org/designsquad/pdf/parentseducators/DSN_NASA_MissionSolarSystem_Rob oArm.pdf

Foam Rockets: http://www.nasa.gov/pdf/295787main_Rockets_Foam_Rocket.pdf

\section{$\underline{\text { Best Practices }}$}

Engineering Education and Enrichment Programs:

- Select challenging content and curriculum that is inquiry-based and experiential.

- Identify lessons that reflect real-world applications.

- Promote NASA curriculum that reflects state and national education standards.

- Provide teachers the opportunity to participate in an inquiry learning environment.

- Supply all curriculums for teachers so they have access and time to hone their science knowledge and hands-on teaching approach.

- $\quad$ Select speakers that are role models for STEM engagement.

- Focus on developing teachers' capabilities and knowledge to teach content and subject matter.

- Provide opportunities to address teachers' classroom work and the problems they encounter in their school settings.

\section{Logistics:}

- Plan early for optimum date, conference location reservation, and hotel booking.

- Select a theme with activities and speakers that teachers will find beneficial.

- Research curriculum, speakers, and activities that will provide new and innovative ideas for the classroom. 
- Utilize NASA's unique resources in space exploration for technology, speakers, and curriculum.

- Recruit judges for the LiftOff applicants to insure all applications are reviewed and selection is done in a timely manner.

- $\quad$ Selection of teachers is made in early May and teachers are notified.

- Intersperse hands-on activities with speakers.

- Always ask speakers if their power point presentations and materials can be shared with teachers. Teachers enjoy sharing the presentations with their students and in teacher training.

- Provide teachers with a notebook for the week with hard copy curriculum activities and put all guides, presentations, power points, and resources on a USB or DVD for their use in the classroom.

- Have one individual designated as the photographer. Teachers enjoy having their photo taken with speakers, especially the astronauts. Clear the time schedule with the speaker prior to offering the photo opportunity. It speeds up the process if one person is taking all photos. We then provide a DVD with all photos to the teachers on the last day of the summer institute.

\section{$\underline{\text { Program Evaluation Results }}$}

Each LiftOff program is evaluated during the workshop by participants. Speakers, tours, activities, and lesson plans are evaluated specifically during the week. A follow-up evaluation is provided to each program participant six months after LiftOff to evaluate the usefulness of the materials, ways the activities have been utilized, numbers reached through direct classroom instruction, numbers reached during outreach activities, and numbers of additional teachers trained.

Evaluation results show:

\begin{tabular}{|l|c|}
\hline Average number of students reached by each teacher & 121 \\
\hline Average percentage of Boys and Girls reached & $49 \%$ Boys \\
& $51 \%$ Girls \\
\hline Percentage of minority participation & $16 \%$ African American \\
& $40 \%$ Hispanic \\
& $2 \%$ Native American \\
& $3 \%$ Asian \\
& $39 \%$ Anglo \\
\hline Activities used in the classroom & $100 \%$ use Teacher Features \\
& $90 \%$ have used curriculum provided \\
while an additional 10\% plan to use \\
curriculum in future when it fits into \\
lesson plans
\end{tabular}




\section{Liftoff Spinoffs}

LiftOff Alumni continue to express their gratitude for additional educational opportunities that are provided because they attended a LiftOff Summer Institute in the past. The exposure to NASA research, opportunities, and data enhances not only the teacher's knowledge but spills into the minds of their students, our next generation of scientists and engineers. Here are five examples:

- Protein Crystal Growth ${ }^{23}$ - Former LiftOff participants and their students participated in a NASA experiment where they studied protein crystallization, worked beside NASA scientists and engineers in loading protein samples for flight, visited Marshall Spaceflight Center to learn about crystallography, visited with astronauts, and followed Richard Garriott's flight on the Russian Soyuz as he launched with their experiment and flew the crystals on the International Space Station.

- LiftOff Alumni teachers developed an experiment re-enacting and updating two of Christa McAuliffe's experiments that would have flown had the Challenger not exploded upon launch. These "Challenger's Lost Lessons" ${ }^{24}$ and selected LiftOff teachers flew on NASA's C-9 weightless wonder aircraft, commonly referred to as the "Vomit Comet." Students in classrooms across the nation followed this flight, conducting the same experiments in their classrooms to compare to those flying in microgravity, simulated lunar gravity and Mars gravity. Robots were built by students during a competition and one design selected for adaption to fly during the mission.

- Two Liftoff Alumni participants are currently Einstein Fellows ${ }^{25}$ in Washington, D.C. The Albert Einstein Distinguished Educator Fellowship (AEF) Program provides a unique professional development opportunity for accomplished K-12 educators in the fields of science, technology, engineering, and mathematics (STEM) to serve in the national education area. Fellows spend eleven months working in a Federal agency or in a U.S. Congressional office, bringing their expensive knowledge and experience in the classroom to education program and/or education policy efforts. Both educators, from different states, credit LiftOff for their innovative space science activities which helped them win the opportunity to become fellows.

- LiftOff teachers assist with workshops at annual professional development meetings such as the Texas State Conference for the Advancement of Science Teachers ${ }^{26}$ and the National Science Teacher Association ${ }^{27}$ meeting, sharing activities and knowledge from the LiftOff Summer Institute during workshops and at the TSGC exhibit.

- Teachers have reported during LiftOff that they have never felt as valued as they do during LiftOff. To have astronauts, engineers, and scientists share stories about the importance of teachers from their past, who help to shape their lives and careers, is powerful and beneficial. Teachers leave with a renewed spirit and enthusiasm.

\section{Participant Feedback}

In the words of LiftOff attendees:

$>$ "Best experience of my $23+$ year teaching career."

$>$ "I am amazed at what you are able to do for teachers. This is a lifetime experience." 
$>$ "I feel truly blessed to be able to attend, motivated to teach students, and more confident to discuss space and conduct labs. Thank you, thank you, and thank you!"

$>$ "The LiftOff Institutes are the best I've ever been to (and I've been to many.) I've learned so much about space exploration in the last two summers and my students love all the activities."

$>$ "LiftOff is the single most valuable subject matter training I have ever been involved with. It informs, equips, and inspires teachers to do the same with their students."

$>$ "The program was extremely well planned, very professionally orchestrated, and provided a wealth of outstanding information I have been able to share with students and colleagues."

$>$ "The most organized, most well-planned, most useful, most helpful, most applicable teacher workshop I have participated with in my entire teaching career of $21+$ years."

\section{Conclusion}

The LiftOff program provides an example of how a successful program can evolve, beginning with an imported program, changing as NASA foci and national standards changed, selecting current and relevant projects and activities to spark student interest in STEM learning and engagement, and implementing week-long innovative activities that motivate educators to replicate lessons and activities in classrooms across the nation. The authors believe that the keys to success for the program are:

1. Advertise early and widely to encourage optimum participation.

2. Target activities to what the teachers must teach in the classroom.

3. Identify speakers, activities, and tours that excite educators to implement new lessons in their classrooms that will spark student interest in STEM education.

4. Use NASA's unique assets in space-related items to capture and maintain interest both for participants and their students.

5. Utilize the train-the-trainer aspect of the program - this provides tremendous leverage.

6. The active participation of astronauts in the program.

7. The provision of classroom-ready materials matched to educational standards to the teachers as they finish the program.

8. Word-of-mouth program promotion among teachers - in the words of LiftOff attendees, "Best experience of my 23+ year teaching career." "I am amazed at what you are able to do for teachers. This is a lifetime experience." "I feel truly blessed to be able to attend, motivated to teach students, and more confident to discuss space and conduct labs. Thank you, thank you, thank you!"

The LiftOff Summer Institute workshops have shown that the excitement that teachers and students feel about space science and exploration can be tapped to enrich science, technology, engineering and mathematics. The workshops also provide teachers the rare - for some, unique - opportunity to spend a week working with professional scientists and engineers. 


\section{$\underline{\text { References }}$}

1.http://www.nasa.gov/offices/education/about/index.html

2. http://www.nasa.gov/offices/education/programs/national/spacegrant/home/index.html

3. http://www.nasa.gov/offices/education/programs/national/spacegrant/home/Space_Grant_Consortium_Web $\underline{\text { sites.html }}$

4. http://www.tsgc.utexas.edu/liftoff/

5.http://www.nasa.gov/centers/ames/home/index.html

6. http://www.lpi.usra.edu/

7.http://www.utexas.edu/

8. http://unitedspacealliance.com/

9. http://www.hmns.org/

10. http://www.moodygardens.com/

11. http://www.hmns.org/index.php?option=com content\&id=107\&Itemid=115

12. http://www.challenger.org/

13. http://aerospacescholars.jsc.nasa.gov/

14. Bruner, J. (1960). The Process of Education. Cambridge, MA: Harvard University Press

15. Kolb. D. A. and Fry, R. (1975) Toward an applied theory of experiential learning. in C. Cooper (ed.), Theories of Group Process, London: John Wiley.

16. http://www.bayerus.com/msms/web_docs/compendium.pdf

17. http://www.nasa.gov/offices/education/programs/national/nes2/home/index.html

18. http://www.nasa.gov/offices/education/programs/national/summer/home/index.html

19. http://spacecenter.org/education-programs/teacher-programs/teachers-seec/

20. http://www.spacestory.com/intro.htm

21. http://www.nextgenscience.org/

22. http://www.corestandards.org/the-standards

23. http://www.tsgc.utexas.edu/protein/selected $03 . h t m l$

24. http://er.jsc.nasa.gov/seh/////Christa_McAuliffe_Lost_Lessons.pdf

25. http://www.einsteinfellows.org/application.html

26. http://statweb.org/cast

27. www.nsta.org 